\title{
Impact of gender and region on attitude towards gay and lesbian on adolescents
}

\begin{abstract}
Present study is an effort to explore the impact of gender and region on the attitude of adolescent girls and boys students towards lesbian and gay people. Present study includes a sample of 100 rural students (50 male and 50 female) and 100 urban students (50 male and 50 female), selected randomly from colleges of Aligarh. Data was gathered by The Attitudes toward Lesbians and Gay Men Scale of Herek.1 Results reveal that adolescents belong to rural areas have more negative attitude toward gay and lesbian people in comparison to urban area students. It was also found that female have more negative attitude towards lesbian and gay people. It can be concluded that students from rural areas are more negative than adolescents from urban areas for Lesbian and Gay. It may be happen because students from urban areas share a combined global culture and more freedom than to the students of rural areas that affects their attitude and thinking. As well as girls face more restrictions than boys that may alter their attitude towards those things that are against laws and culture.
\end{abstract}

Keywords: gender, region, lesbian, gay, attitude
Volume 9 Issue 6 - 2018

\author{
Deoshree Akhouri, Kehksha, Maria Madiha \\ Department of Psychiatry, Aligarh Muslim University, India
}

Correspondence: Deoshree Akhouri, Department of Psychiatry, Aligarh Muslim University, Aligarh, Uttar Pradesh, India,Tel 91-8439894327, Email drdeoshreakhouri@gmail.com

Received: June 23, 2018 | Published: November 16, 2018

\section{Introduction}

Concept of being lesbian and gay in present era is not yet acceptable as it is spreading all over the world. Though most of the countries have legitimized the relationship of gay and lesbian people, the attitude of people towards them is still obnoxious. Most of the countries take homosexuality as an offence and punish homosexual people through fines, imprisonment or even sentence to death. Homosexuality in Indian culture is still unacceptable for both civil society and governance. For example- section 377 of Indian penal code says, having sex with the person of same gender is a crime and punishable offence in Indian constitution. In spite of being a crime in Indian law, there were about 2.5 million registered gay people living in India in 2012. ${ }^{2}$ This data was just based on the self-declaration of homosexual people that may be much higher than recorded statistics because homosexual people suffer discrimination in every sphere of their life and considered as immoral individual. All the people of gay and lesbian community have to suffer prejudices and weird behavior of people that is deeply rooted in believes and culture of society. ${ }^{3}$ Hostile and rejecting attitudes towards homosexuals are commonplace. Physical attacks on homosexuals, discrimination against lesbians and gay men by employers, personal rejection by family and neighbors, and derogatory jokes demonstrate widespread homophobia. ${ }^{4}$ Members of homosexual group face various kind of injustice due to lack of social recognition that affects many aspects of their personality. They are more likely to face intolerance, discrimination, harassment, deride and threat of violence for their orientation toward homosexuality. ${ }^{5}$ They constantly suffer from social exclusion that includes market places, schools, workplace, and neighbors as well. Even they are not allowed to enjoy the same legal rights and protection as other citizens do. In labor market the majority of such people have to hide their orientation towards same sex. This pressure is high for young lesbian and gay people otherwise they could lose social support, familial detachment, peer group teasing and disturbance in their social network, harassment at school etc. which can lead them to have social isolation, school dropout, ill mental health and sometimes homelessness. ${ }^{6}$

\section{Objectives}

Present study attempted to accomplish the following objectives

1. Explore the effect of gender and region on attitude towards lesbian and gay.

2. Differentiate rural and urban areas participants on attitude towards lesbian and gay people.

3. Differentiate adolescence girls and boys on attitude towards lesbian and gay people.

\section{Hypotheses}

The present study was carried out to test the following hypotheses

1. Gender and region influence the attitude of adolescence girls and boys towards lesbian and gay significantly.

2. Participants belong to rural areas have more negative attitude towards lesbian and gay than to participants of urban areas.

3. Adolescence girls have more negative attitude towards lesbian and gay than adolescence boys.

\section{Methodology}

Sample: Sample of the present study was adolescent boys and girls students. Therefore, a total of 200 adolescence students from under graduation (ages 15-19) were selected through purposive random sampling technique. An equal number of participants were drawn from colleges of Aligarh district Uttar Pradesh. All the participants were divided into two categories based on rural and urban area and gender as well. Thus, the study consists of four groups of as male, female, rural and urban.

Tool used in study: Attitude toward Lesbian and Gay Scale is a 
self-administered scale used for measuring the attitude of girls and boys students. This scale was developed by Herek ${ }^{1}$ and modified in 1994. ${ }^{1}$ This scale contains 10 statements, 5 for measuring attitude towards Lesbian and 5 for gay people. Seven point Likert type scale was used in this study. Statements of this scale ranged from strongly disagree to strongly agree. The ATLG scale has high level internal consistency. Test retest reliability for this scale has been found .80 . Alpha for this scale has been found .85 for students and 80 for nonstudents adult sample. Higher score demonstrates negative attitude of the participants towards lesbian and gay people.

Performance method: The data were collected individually in the college campus. Participants were taken into confidence and understood the goal of the study. Thereafter, questionnaires were distributed among students. They were requested to give responses for each statement. Then all the questionnaires were collected for statistical treatment.

Analysis of data: After collecting data, it was analyzed by the SPSS 16.0. For the purpose of study, mean, S D and t value were calculated and results were obtained that are presented in Table 1.

Findings of the data show the mean score, SD and t value of the rural and urban girls. The mean score of attitude towards lesbian and gay for rural and urban girls was found 50.36 and 37.12. It means girls from rural areas are more negative than to girls of urban areas. T-score was found 4.956 that are significant at 0.05 level of significance. Comprehensively, we can state that girls belong to rural areas and urban areas have different attitude towards lesbian and gay people (Table 2). Comparison between boys belong to rural areas and urban areas in relation to their attitude towards lesbian and gay was done by $\mathrm{t}$ - test and mean value, $\mathrm{SD}$ and $\mathrm{t}$ score was obtained. The mean value of attitude of rural and urban areas boys toward lesbian and gay man were found 43.94 and 36.84 respectively. It means rural areas boys have more negative attitude than to boys of urban areas towards lesbian and gay people. T-value was found 2.823 which are significant at 0.05 level of significance. Obtained t-value shows that rural and urban boys differ significantly with each other in terms of attitude towards lesbian and gay people (Table 3). To compare girls and boys on attitude towards lesbian and gay people, t-test was used. The mean value of attitude of girls and boys towards lesbian and gay people were found 44.54 and 40.39 respectively. Both girls and boys have negative attitude towards lesbian and gay people but comparatively, girls have more negative attitude than boys towards lesbian and gay people that is evident from above table. T-value was found 2.167 which are significant at 0.05 level of significance. It indicates significant difference between girls and boys on attitude towards lesbian and gay people.

Table I Impact of region on attitude of adolescence girls toward lesbians and gay people

\begin{tabular}{lllllll}
\hline Group & N & Mean & Std. deviation & t-value & d.f. & Level of significance \\
\hline Rural girls & 50 & 50.36 & 11.389 & 4.956 & 49 & $\mathrm{P}<0.05$ \\
Urban girls & 50 & 37.12 & 17.058 & & & \\
\hline
\end{tabular}

Table 2 Impact of region on attitude of adolescence boys toward lesbians and gay people

\begin{tabular}{lllllll}
\hline Group & N & Mean & Std. deviation & t-value & d.f. & Level of significance \\
\hline Rural boys & 50 & 43.94 & 12.175 & 2.823 & 49 & $P<0.05$ \\
Urban boys & 50 & 36.84 & 10.576 & & & \\
\hline
\end{tabular}

Table 3 Impact of gender on attitude of adolescence boys and girls toward lesbians and gay people

\begin{tabular}{lllllll}
\hline Group & N & Mean & Std. deviation & t-value & d.f. & Level of significance \\
\hline Girls & 100 & 44.54 & 15.286 & 2.167 & 99 & $P<0.05$ \\
Boys & 100 & 40.39 & 11.893 & & &
\end{tabular}

\section{Result and discussion}

First hypotheses were found to be true as the findings says that region influences the attitude of adolescence girls and boys towards lesbian and gay significantly. ${ }^{7}$ Regional environment is more important to shape one's thinking, attitude, perception, imagination etc. Culture of one particular region affects the values of individuals thoroughly. Rural areas in India are still a symbol of old tradition where particular rituals and customs are followed. That is why in our study, students from rural areas have been found to be more negative for lesbian and gay people. On the other hand, urban areas of India are developing incredibly. People from urban areas are living an adopted foreign culture where everything has been taken for granted. There is not a big deal for the people of urban areas, if they violet the traditional values. Therefore students from urban areas showed less negative attitude towards lesbian and gay people. Gender difference on attitude towards lesbian and gay people has been found clearly.
Result demonstrated that girls are more negative for lesbian and gay people than boys. The reason behind this may be the restrictions over the girls. ${ }^{8}$ In India, the girls are still supposed to follow all rules and customs prevalent in society. From cradle to grave, they have to be the leader of such customs and traditions. This may definitely responsible to influence their attitude towards those things that are against their culture. Thus our hypothesis that gender effects the attitude toward lesbian and gay people has been found to be true that can be seen through the findings.

\section{Conclusion}

Findings of the study have very important implication not only for gay and lesbians but also for legal activists who always found to be stand on either side. In India where $60 \%$ population is still living in villages, through this study it has been clearly found that students from rural areas have negative attitude towards lesbian and gay people. Furthermore, girls have been found to show more negative 
attitude towards lesbian and gay people than boys that is evident from the findings of the study. Therefore, through our study, it is proved that there is a strong need to look for a middle way for both the groupshomosexual people and civil society. So that the benefits of both can't be encroached.

\section{Limitations and suggestions for the study}

First and the most important limitation of the present study is that, it was conducted on a small sample size and only on the participants of a single city that may affect the view point of the participants due to cultural and geographical environment. So if the large sample size would be taken, there is enough probability to alter the result of the present study. Other one is the participants were approached individually to collect data that could be a cause to hide their real perspective towards lesbian and gay from the researcher and the desire to be more liberal may counter their thinking. Hence to control this limitation, the tool should be administered in group so that participants can feel easy and reveal their true responses in Indian culture where to be lesbian or gay is considered a disgusting act.

\section{Acknowledgements}

None.

\section{Conflict of interest}

The author declares that there is no conflict of interest.

\section{References}

1. Herek GM. Attitudes toward lesbians and gay men: A factor analytic study. J Homosex. 1984;10(1-2):39-51.

2. India has $2.5 \mathrm{~m}$ gays, government tells supreme court. BBC News. 2016.

3. Ventura LA, Lambert EG, Bryant M, et al. Differences in attitudes toward gays and lesbians among criminal justice and non-criminal justice majors. American Journal of Criminal Justice. 2004;28(2):165-180.

4. Reasons CE, Hughson Q. Violence Against Gays and Lesbians. Journal of Offender Rehabilitation. 1999;137-159.

5. Chatterjee S. Problems Faced by LGBT People in the Mainstream Society: Some Recommendations. International Journal of Interdisciplinary and Multidisciplinary Studies. 2014;1(5)317-331.

6. Violence against LGBT groups still prevails in India. DNA India. 2014.

7. Stephen Murray O. Homosexualities. USA: University of Chicago;2000:1-515.

8. Sekher TV, Hatti N. Discrimination of Female Children in Modern India: from Conception through Childhood. Institute for Social and Economic Change. 2005. 